\title{
SENSOR AND SATELLITE ASSET ALERT AND MANAGEMENT SYSTEM (SSAAMS)
}

\author{
S.A.Plumb ${ }^{1 *}$, M. Watt ${ }^{1}$, C.M. Ellis ${ }^{1}$, T. Sajwaj ${ }^{2}$, S.G. Ross ${ }^{2 *}$, P.J. Graham ${ }^{3 *}$ N. Metje ${ }^{4}$, \\ D.N. Chapman ${ }^{4}$, E. Stewart ${ }^{4}$, A.D. Quinn ${ }^{4}$ and L. von der Tann ${ }^{4}$ \\ ${ }^{1}$ Amey. Ltd, Oxford, United Kingdom \\ ${ }^{2}$ Rezatec Ltd., Harwell, Oxfordshire, United Kingdom \\ ${ }^{3}$ Senceive Ltd., London, United Kingdom \\ ${ }^{4}$ School of Engineering, University of Birmingham, United Kingdom \\ * Corresponding author
}

\begin{abstract}
The Sensor and Satellite Asset Alert and Management System (SSAAMS) aims to improve the monitoring of linear infrastructure assets to minimise failure, thereby reducing maintenance costs and extending asset lifetimes. The application of satellite-based Differential Interferometric Synthetic Aperture Radar (DInSAR) enables the mapping of ground deformation across wide areas. Using this approach to identify areas of historic ground movement enables targeted risk-based installation of ground-based sensors on physical assets which then provide continuous accurate data at higher resolution for at risk locations. Launched in 2015, the data available from the ESA Sentinel-1 satellite provides the ability to undertake regular low-cost monitoring of distributed network assets identifying high risk areas for sensor deployment. On the ground bespoke sensors provide information on tilt, displacement, temperature, soil moisture and photography remotely relayed for immediate analysis and alert notification to infrastructure operators

This paper summarises the initial project findings from comparing historical satellite data versus an existing array of ground-based tilt-sensors installed on rail infrastructure; demonstrating that similar trends can be observed from satellite and ground-based measurements. The paper concludes with a summary of ongoing control trials that will further calibrate the satellite and sensor measurements using radar reflectors. Additional deployment scenarios currently being trialled include reservoirs, highways and quarry embankments. For each deployment, the paper discusses the value that both datasets bring to the asset operators, how this will feed into a proactive asset management process and the benefits of having a unified platform for interacting with both satellite and ground sensor data.
\end{abstract}

\section{Introduction}

Ground movement is a significant cause of failure for many types of built infrastructure. Amey and its clients regard an enhanced Asset Management (AM) system like SSAAMS will provide digital asset knowledge enabled decisions to be made. The primary types of assets where we see SSAAMS as an opportunity are primarily linear assets such as road and rail networks. Ground movement can result in either direct displacement of roadway or track-bed or indirect impact from the movement of associated earthworks and embankments. Identifying and monitoring locations at risk allows proactive maintenance to be undertaken by infrastructure operators minimising the disruption caused by sudden unexpected events. The risks and likelihood of failure are further exacerbated by extreme weather, which is predicted to increase (Thompson et al., 2017).

Established asset survey and ground-based sensor technology such as the BGS PRIME system (Proactive Infrastructure Monitoring and Evaluation) or Senceive tiltmeter technology already allow for real-time monitoring and updates of specific local assets (e.g. rail embankments, retaining walls, bridges etc.) but their deployment is often based on the occurrence of past movement events or the identification of specific risk factors (e.g. underlying soils and geology, slope angle etc.). Deployment and maintenance of any sensor array is a significant investment for any operator so ensuring that these resources are being deployed efficiently is paramount.

The SSAAMS project aims to extend regular asset monitoring to the full extent of the network by leveraging satellite-based mapping of ground movement. Initially retrospective analysis of existing networks allows for locations of historic movement to be identified. The risk and consequence of failure for any of these locations can then be determined with the option to continue regular satellite monitoring or undertake a follow-up site inspection or sensor deployment. Unlike traditional asset inspections which may have years between surveys, repeat satellite observations can be made up to every six days enabling early identification and intervention before major incidents occur.

The satellite monitoring component of SSAAMS is not intended as a replacement for surveys or sensors but instead as a complement to these established techniques. In addition, a unique feature of the project compared to previous applications of satellite measurement will be the correlation of satellite with ground sensor data. Using a series of control sites the satellite measurements of movement will be calibrated against ground 
sensor data providing asset managers with assurance of the suitability and accuracy of satellite data for wider area monitoring.

The ultimate goal of the project is to provide a comprehensive monitoring service for infrastructure operators that allows analysis, visualisation and alerts across the complete asset footprint; combining data from satellite and sensors in a single user-friendly reporting platform.

\subsection{Satellite monitoring}

The techniques for monitoring ground deformation from satellite are well established but have often been limited for long-term commercial applications due to the cost of the data required. The SSAAMS project is therefore primarily focussed on leveraging the open source data available from the ESA Sentinel-1 (Torres et al., 2012) program launched in 2015 which provides low-cost global coverage with a 6-12 day repeat cycle.

Differential Interferometric Synthetic Aperture Radar (DInSAR) techniques employ the phase component of radar waves of two (or more) SAR images acquired over the same location at regular intervals to produce an interferogram, or the patterns of interference between two SAR data sets. Interrogation of the interferograms permit the creation of Digital Elevation Models (DEM) with meter accuracy and large area terrain motion estimation with sub-centimetric accuracy (Ferretti et al., 2001). The first DInSAR methods were developed nearly 30 years ago (Gabriel et al., 1989) and typically used short time series (2-4 image dates) of SAR data. Contemporary DInSAR approaches typically use much larger time series (e.g. 20+ image dates) to create statistically robust measurements of terrain motion.

This shift in methodology reflects the quality of available data and the end-use of the analysis. Historically, DInSAR methods have been applied to assess large-scale ground motion phenomena in the areas of seismology (Dalla Via et al., 2012), glaciology, landslides (Singleton et al., 2014) and ground subsidence (Castellazzi et al., 2016) due to the coarse spatial resolution of the early SAR satellite sensors (e.g. ASAR, ENVISAT). More recently, new satellite-based SAR sensors have been deployed to collect data at higher spatial resolutions (e.g. Cosmo SkyMed) and with greater temporal frequency (e.g. Sentinel-1). These datasets have much greater potential for monitoring the more localised ground movements that can be expected to impact built infrastructure. Modern computing techniques further support this localised high frequency approach by enabling automated analysis workflows that can rapidly analyse and publish results as new images are captured.

\subsection{Ground-based sensors}

Whilst remote sensing technologies such as DInSAR can cover large areas with their temporal resolution is set by the number of overpasses, ground-based sensors measure deformation or other properties locally over a small area with high accuracy providing continuous data series through remote data logging (Smethurst et al., 2017). Two kinds of point sensors can be distinguished: Those that enable monitoring of deformation or water related parameters within the ground including inclinometers, extensometers, and piezometers and technologies that measure displacements and/or climate/ weather related factors at surface. The former instruments are installed in boreholes and due to the cost of site access for drillings as well as a nervousness of exacerbating instability issues for older road and rail infrastructure assets are not usually suitable for large-scale monitoring schemes. The latter include in particular tilt meters and weather stations, as well as soil moisture sensors which can be installed in simple handdug trenches. The correlations between these measurements and the condition of the earthwork as well as possible failure mechanisms of the underlying slope are not fully understood (Smethurst et al., 2017), but tilt sensors in combination with infrared cameras have been, for example, deployed as an early warning system for slope movements on a range of railway assets (Network Rail, 2015).

\section{Methodology}

The SSAAMS project is ongoing with completion scheduled for August 2019. Therefore, many of the field tests and trials are not yet complete with critical periods of testing continuing to take place in winter and spring 2019. The focus for this paper is therefore on initial assessment of a $70 \mathrm{~km}$ stretch of railway line between Folkestone and Dover. This wide area satellite assessment is complemented by comparison of satellite observations with a previously established ground sensor array installed on the sea wall that protects a section of the line on approach to Dover.

The "Dover Sea Wall" is a retaining wall on a section of the track between a cliff and the beach. Originally built around a timber frame, the wall had been suffering from costal erosion and a major failure occurred on $24^{\text {th }}$ December 2015. This occurred following a heavy storm resulting in sinkholes appearing underneath the track-bed that caused large voids and track settlement. The line was closed indefinitely, and while repair works were carried out Senceive provided a network of sensors to monitor the sea wall during the reconstruction works.

\subsection{Satellite monitoring}

Rezatec acquired 98 SAR images covering the period from $1 \mathrm{st}$ January 2016 to $31^{\text {st }}$ December 2017, a data set that includes 48 descending images and 50 ascending images. While most of these data sets were captured at 12-day intervals, the period from January-August 2016 have 24- and 36-day gaps due to data unavailability. The ascending and descending data sets were processed separately but using identical workflows:

- Multi-looking and co-registration;

- Interferogram generation;

- Preliminary model inversion to estimate terrain motion;

- Secondary model inversion to mitigate atmospheric effects; and,

- Geo-coding of terrain motion outputs. 
Preliminary DInSAR measurements from Sentinel-1, are calculated as approximate points with $+/-9-12 \mathrm{~m}$ positional uncertainty on the ground (Costantini et al. 2017), were aggregated and summarised for $100 \mathrm{~m}$ rail segments. To account for geo-positional uncertainty of DInSAR measurements and to improve the robustness of terrain motion estimates, each $100 \mathrm{~m}$ rail segment was buffered by $20 \mathrm{~m}$ to generate terrain motion averages over the study period.

\subsection{Ground-based sensors}

Senceive's wireless remote condition monitoring platform FlatMesh was identified to meet the ground sensing requirements of the project. FlatMesh allows the operator to connect combinations of sensors to suit the needs of the project. These might include linear potentiometers for submillimetre displacements or piezometers to measure pore water pressure for geotechnical assets. Each sensor node is wireless, battery powered and operates on the same network, using other nodes to relay data samples back to the Gateway, a solar powered base station. The data is finally forwarded to the cloud using the cellular network or other available networking infrastructure. The FlatMesh network is self-forming to allow a "place and forget" deployment strategy and self-healing so sensors can find different routes to the gateway, accommodating the possibility of sensors being damaged in the difficult rail and construction environment.

The most versatile compatible sensor for monitoring ground or infrastructure movements is the tiltmeter, offering measurements to a resolution of $0.0001^{\circ}(0.00175 \mathrm{~mm} / \mathrm{m})$ installed in any orientation. The tiltmeters can be used with a wide range of bespoke fixings which can be used to monitor a particular attribute of a structure. For example, installation on a railway sleeper to measure track cant and twist or magnetically attached to an cast iron tunnel to measure tunnel deformation (Maddison and Smith, 2016). When measuring longitudinal settlement, the most appropriate fixing in the context of the sea wall is a series of rigid "daisy-chained" beams. In this instance, the client required a rapid response system where requested that sensors were placed directly onto the wall to primarily measure lateral movement (i.e. the wall tipping towards the beach) whilst giving indicative settlement measurements (i.e. the wall sinking towards the beach).

Figure 2.1 Installed sensors on top of Dover Sea Wall

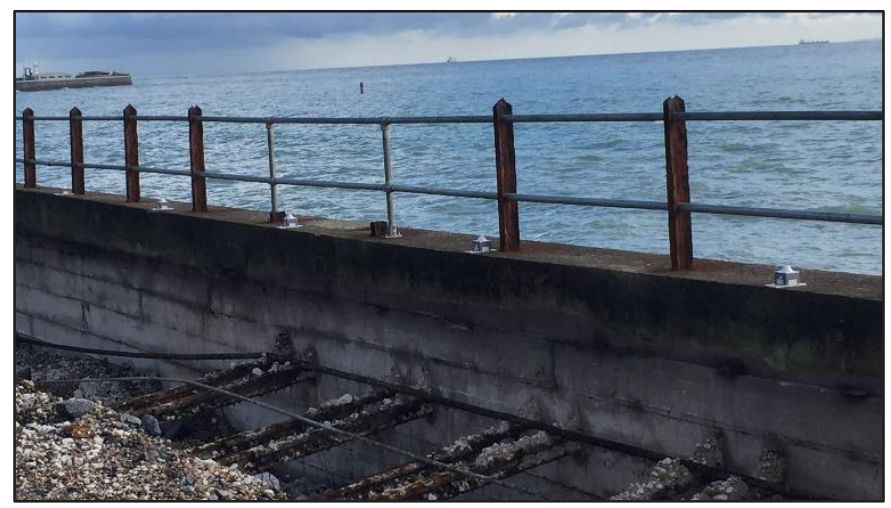

Senceive installed 168 tilt sensors, placed directly on the parapet of the sea wall. Each sensor was installed at three or six metre centres along the length of the wall, monitoring a total length of approximately 700 metres (Figure 2.1). Sensors were installed in February 2016, then extended to the full complement of sensors on 14 March 2016 before monitoring ceased in August 2016.

\section{Results}

The results are discussed in the context of both independent analysis of the satellite and sensor sources and an integrated comparison of the two. Further discussion of initial findings from ongoing project deployment scenarios can be found in the conclusions.

\subsection{Satellite monitoring}

The larger area containing the Dover Seawall (Figure 3.1) processed for terrain motion contained $71.3 \mathrm{~km}$ of rail track, excluding rail tunnels and narrow-gauge track) and was divided into $100 \mathrm{~m}$ segments. Of the 713 rail segments, 57 segments $(8.0 \%$ of the local rail network) had too little DInSAR data of sufficient quality to be analysed. Of the remaining 656 rail segments, slightly more than $97 \%$ exhibited little or no terrain motion ( $<4 \mathrm{~mm}$ movement/year). Two areas of significant terrain motion were observed: the Dover Sea Wall and sections of rail near Folkstone previously identified by Network Rail as a location of significant ground motion.

Figure 3.1 Extent of satellite terrain motion monitoring

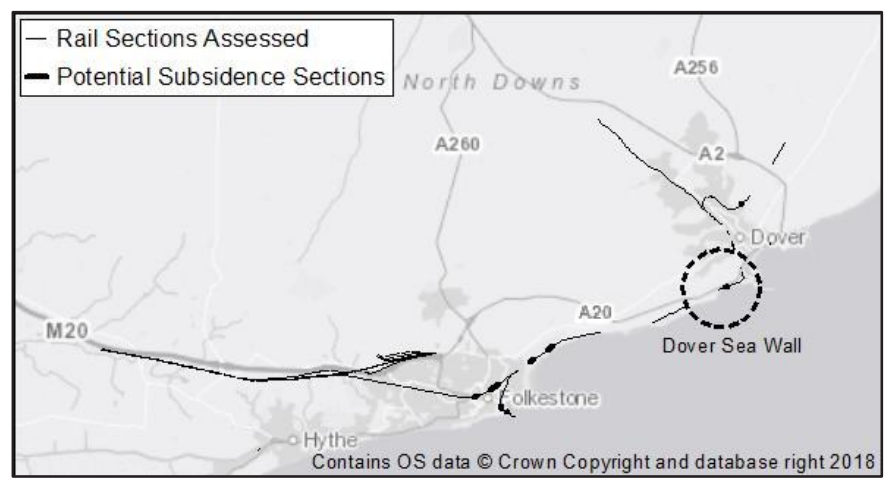

\subsection{Ground-based sensors}

Figure 3.2 describes the settlement profile of the Dover Sea Wall from Senceive's tilt sensor array. Across the monitoring zone, there are indications of settlement that occurred between March and August 2016.

Figure 3.2 Measured displacement of the Dover sea wall in March and August 2016.

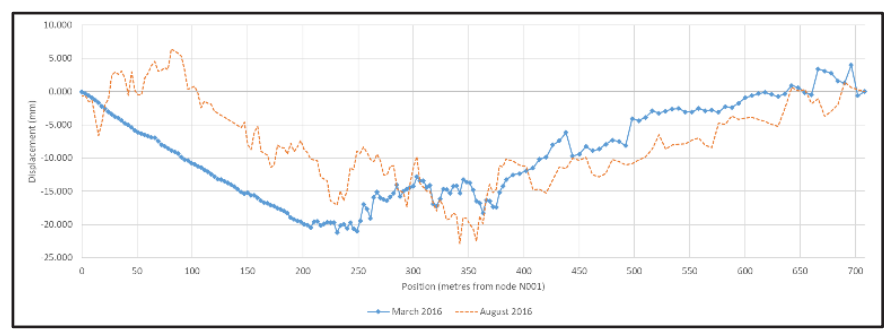




\subsection{Integrated analysis}

During the period of Senceive's in-situ monitoring (April August 2016), the DInSAR measurements associated with the rail segments indicated an average subsidence rate of $5.0 \mathrm{~mm} /$ year on a section of the track coincident with the middle of the Dover Sea Wall. Senceive's ground sensors indicated subsidence rates of $-8.0 \mathrm{~mm} /$ year (Figure 3.3) along the same section. While there are discrepancies between the satellite and sensor data, the spatial and temporal correspondence of the results is highly encouraging for monitoring rail assets.

Figure 3.3 Terrain motion measurements from DInSAR and in-situ sensors for the Dover sea wall.

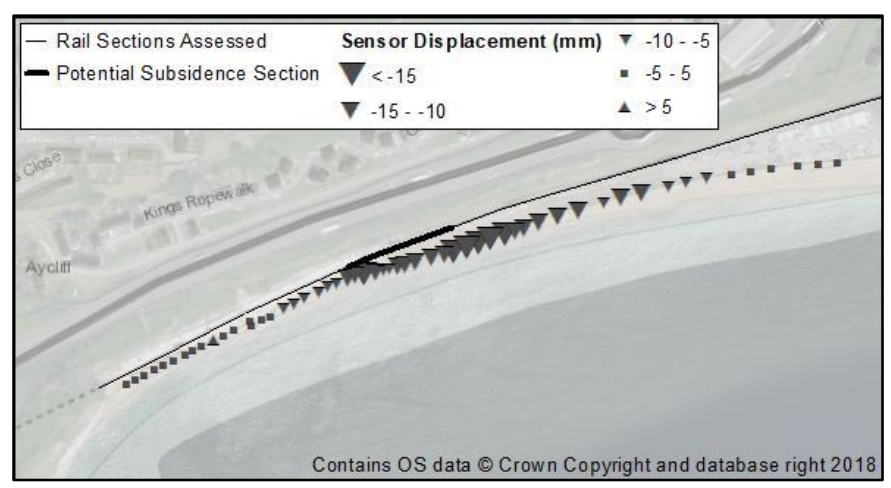

\section{Conclusions}

The retrospective comparison of satellite and sensor data from the Dover Sea Wall has shown that similar temporal trends in ground movement can be observed at the same location. Due to the type and placement of the sensors a precise correlation to calibrate the satellite measurement could not be achieved in this example case; with one of the key challenges being the lack of precise positioning for the satellite observation (estimated positional error $+/-9-12 \mathrm{~m}$ ).

This lack of known precision for the Sentinel-1 imagery is a data limitation that is not easily overcome at source and the targeted use of higher precision commercial satellite data is still a consideration for the project. This does not, however, preclude the use of this Sentinel-1 data for wider area monitoring as the key purpose of satellite monitoring is to identify areas that may be at risk and this can still be achieved across large infrastructure footprints. Improvement can be made however in calibrating the estimated ground movement measurements from satellite by correlating with ground-based sensors in both a controlled field environment and example end user site trials. Achieving an innovative methodology for direct correlation of satellite and sensor data will be a unique feature of the SSAAMS project enabling the satellite measurements and ground correlation with sensors to be reported in terms of actual expected ground movement informing asset management planning and investment.

\subsection{Satellite calibration}

Radar corner reflectors are an established ground-based technology to provide a consistent high intensity radar reflection from a known point. Placed to orient with a specific satellite overpass, corner reflectors can then be manipulated to mimic ground movements that may occur at a site by altering height, orientation or tilt of the reflector.

4.1.1 Test site: The SSAAMS project initially deployed a series of reflectors of varying sizes to establish the minimum suitable size for deployment. Figure 4.1 shows a simple ground mounted reflector used for testing. Initial deployments showed that while smaller reflectors could be detected the optimal size for correlation would be $50 \mathrm{~cm}$ units.

Figure 4.1 Ground mounted $50 \mathrm{~cm}$ corner reflector

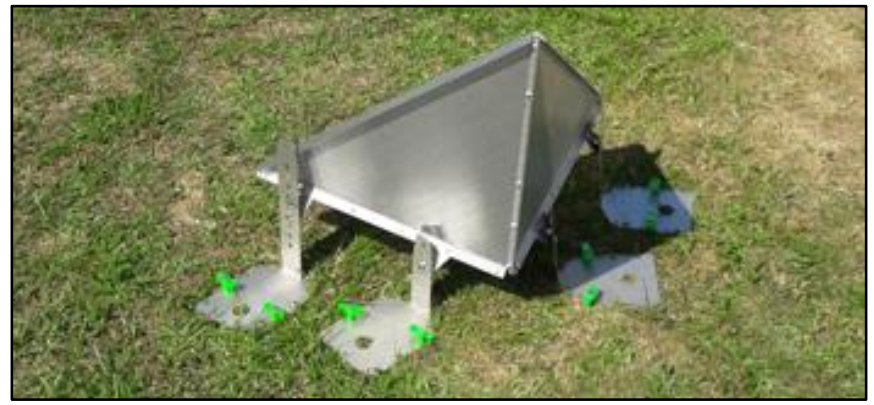

4.1.2 Control site: For correlation testing further control deployments have now been made as shown in Figure 4.2. The stabilised tripod has been used to limit natural ground movement and allow only planned adjustments to be made. A custom mounting system designed by Senceive allows for the orientation, height and tilt of the reflector to be altered with two triaxial tilt sensors recording and confirming the precise changes that are made.

Figure 4.2 Control site reflector deployment

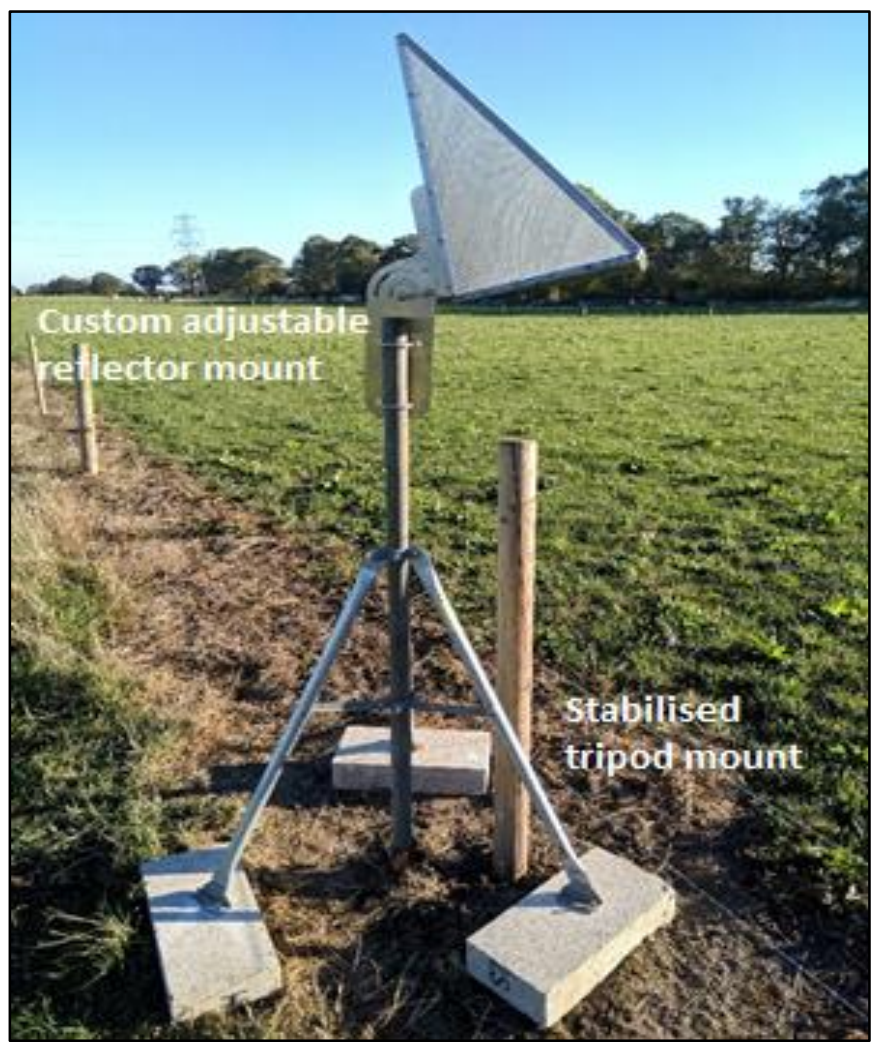


The project is currently undertaking a series of programmed adjustments which will extend over a 3-month period. Once this is complete the data will be suitable for assessing correlation and drawing final conclusions on the achievable accuracy of satellite measurements. Long-term it is anticipated that further correlation sites may be needed to augment the wide area monitoring further. There is also potential for key discrete locations (e.g. railway bridges) to have permanently installed reflectors.

\subsection{Field trials}

The project consortium approached several asset owners who they felt would benefit the most from a combination of longterm satellite monitoring and precise point monitoring. All partners were keen to deploy equipment on a range of asset types to explore the potential use cases for the SSAAMS approach.

4.2.1 Highway embankment: Near to Ripley, Derbyshire, the A38 road sits in a cutting which has a long-standing soil slip. Highways England have in the past attempted to apply remedial works to the site and the site of failure was last inspected in 2015. A new sustained monitoring regime consisting of topographic and invasive survey is currently being devised - in the meantime the opportunity has arisen to deploy a rapid response earthworks kit. Highways England have supported the project with site access and Traffic Management from their own innovation funds in support of SSAAMS.

Ground sensors, installed in November 2018, consist of two rows of 12 tiltmeters installed on aluminium stakes driven into the slope covering an area of approximately $2.2 \mathrm{~km}^{2}$ (Figure 4.3). The tiltmeters act as an early warning system if a slippage were to occur and give an indication to the most active sections of the cutting. In particular, the bottom row of sensors was installed at the crest of the slope toe bulge, which is encroaching the vehicle restraint system (VRS) barrier. The top line of sensors and corner reflectors were installed on the break of slope at the front edge of the top break-back scar where apparent. Corner reflectors have been mounted to two of the stakes to provide additional correlation to longer-term retrospective assessment of the site from satellite installed with separations distances to take both CR's out of the influence of each other, benchmarked from our control site works.

One of the most important parameters in any earthworks deployment is soil moisture. Therefore, in order to satisfy the demand of the project a sensor capable of measuring volumetric water content (v.w.c.) was qualified using Senceive's generic millivolt per volt interface. The sensor chosen is cost effective yet has a resolution to $3 \%$ v.w.c which makes it suitable for deploying several in situations where the root cause of failure is not yet determined. A key requirement was that the system is completely autonomous, to avoid costly repeat visits to take readings.

Thanks to use of entirely wireless equipment throughout the site, Senceive and Amey were able to install all the equipment in one night shift whilst a de-vegetation team were busy clearing the cutting, limiting the labour and traffic management costs which were kindly supplied from Highways England innovation support.

Figure 4.3 Triaxial tilt sensors attached to stakes driven into the earthwork beside the A38 road, Ripley.

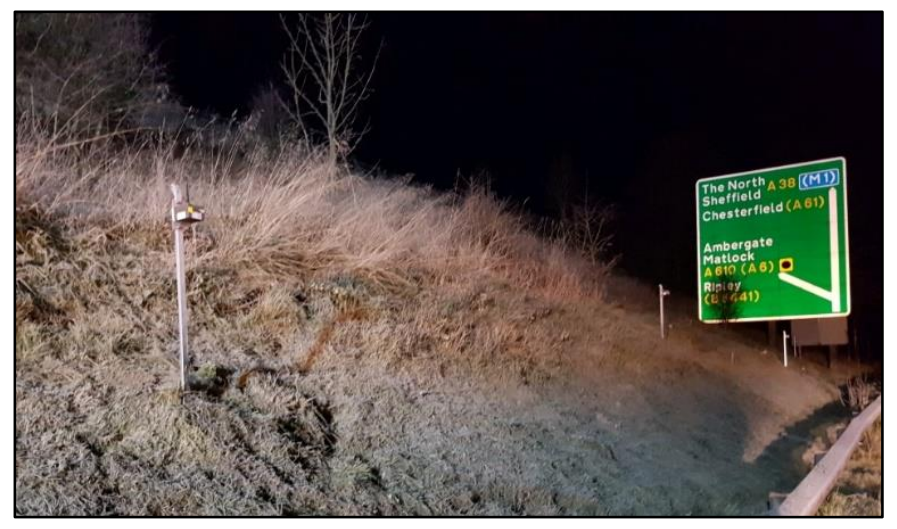

4.2.2 Reservoir dam: Burnhope Reservoir, located in the North Pennines, was created by construction of an earth embankment dam and is operated by Northumbrian Water. It has a typical monitoring schedule; a manual survey is performed on an annual basis and the dam is classified as low risk. Northumbrian Water hope to learn more about the dynamics of the earthwork as the seasons shift. Summer 2018 was especially warm and dry, with the water level dropping to an exceptional low, giving the opportunity to capture the effect of stresses caused by the entire 6.4 million cubic metres of water contained within the reservoir at full capacity.

The nominated approach was to install $86 \mathrm{Nano}+$ triaxial tilt sensors wave return wall of the earthwork dam, covering a length of over 500 metres. Installation of a beam array along the wall was deemed impractical due to access constraints and relentless winds in the area. Northumbrian Water were keen to install a discrete, non-destructive sensor array. Therefore, sensors were attached directly to the dam wall using adhesive in September 2018 and geospatial positions were taken using an RTK network rover based GNSS equipment. The ground sensing solution is therefore an indicative one, as to calculate a vertical displacement, an assumed virtual beam length will be used and calibrated using traditional monitoring techniques.

Figure 4.4 Nano+ triaxial tilt sensor installed on Burnhope Reservoir's wave return wall.

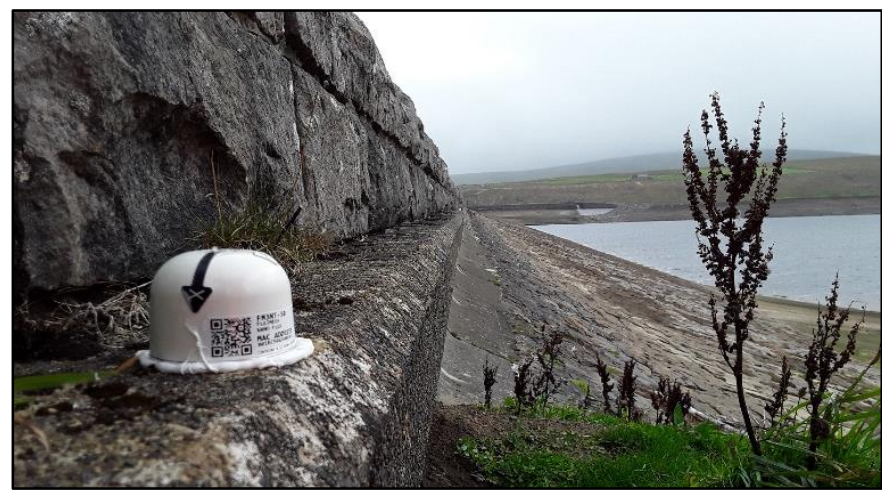


The client was especially pleased with the low-profile nature of the equipment. As the dam wall is open the public, high theft risk items such as an automatic total station would require costly surveillance. By installing the solar powered gateway on the roof of the nearby sluice gatehouse, the entire system was kept away from the public eye.

4.2.3 Railway trackbed: Amey is piling some additional rail infrastructure on a raised section of track in Acton Grange, Warrington. The SSAAMS project has installed 15 track bed FlatMesh triaxial tiltmeter nodes adjacent to the future piled sites. The nodes will measure the cant and twist of the track. Retrospective satellite analysis and ongoing monitoring is being undertaken over an extended section of the track to provide a further use case for the project.

\subsection{New ground sensor developments}

In situations where it is infeasible to install a tilt beam on a structure, e.g. earthworks or delicate structures, it has previously been impossible to measure true displacement with the FlatMesh platform. In order to remedy this, Senceive developed an Optical Displacement Sensor (ODS) which uses a laser to measure distance from the node to a target up to a range of 150 metres when using a reflective target or 50 metres on a natural surface.

A key aim during the development process was that the sensor must be able to detect not only gross movement from a sudden failure but also allow monitoring experts to perform failure prediction based on trend analysis. The sensor is therefore sensitive enough to take readings at a resolution of $0.1 \mathrm{~mm}$, while maintaining the requirements of being completely wireless and a battery life of eight years when taking a sample every 30 minutes. In particular having an optical means of measuring displacement creates an opportunity to measure rail slew and allows the FlatMesh platform to entirely cover the requirements for trackbed monitoring.

\subsection{Optimisation of monitoring schemes}

To ultimately allow an efficient optimisation in relation to the installation and manual reading of ground sensors, a better understanding of the linkage between surface movements and failure mechanisms, as well as the sensitivity of failure mechanisms and the variability of the local geology, is sought Finite element modelling of selected case studies will provide insight into these questions and allow a better understanding of the minimal data requirements for the anticipated findings to be applied to the rail and road infrastructure in the UK.

\section{Acknowledgements}

The project is partially grant funded by Innovate UK with additional funding provided by the project partners, Amey Ltd., Senceive Ltd., Rezatec Ltd. and the School of Engineering at the University of Birmingham. The project is also grateful for the support of industry partners Network Rail, Highways England and Northumbrian Water for access to sites to trial project capabilities. Latest updates can be accessed at https://www.rezatec.com/resources/projects/ssaams/

\section{References}

Castellazzi P et al. (2016). Land subsidence in major cities of Central Mexico: Interpreting InSAR-derived land subsidence mapping with hydrogeological data. International Journal of Applied Earth Observation and Geoinformation 47: 102-111.

Costantini $\mathrm{M}$ et al. Complementarity of high-resolution COSMO-SkyMed and medium-resolution Sentinel-1 SAR interferometry: Quantitative analysis of real target displacement and $3 \mathrm{D}$ positioning measurement precision, and potential operational scenarios. Geoscience and Remote Sensing Symposium (IGARSS), 2017 IEEE International. IEEE, 2017.

Dalla Via G et al. (2012). Resolving vertical and east-west horizontal motion from differential interferometric synthetic aperture radar: The L'Aquila earthquake. Journal of Geophysical Research: Solid Earth, 117(B2).

Ferreti A et al. (2000). Nonlinear subsidence rate estimation using permanent scatterers in differential SAR interferometry. IEEE Transactions on Geoscience and Remote Sensing 38(5): 2202-2212.

Ferretti A et al. (2001). Permanent scatterers in SAR interferometry. IEEE Transactions on geoscience and remote sensing 39(1): 8-20.

Gabriel AK et al. (1989). Mapping small elevation changes over large areas: differential radar interferometry. Journal of Geophysical Research: Solid Earth 94(B7): 9183-9191.

Maddison S and Smith B (2016) Wireless remote condition monitoring opens new monitoring applications in railway tunnel deformation and trackbed. Transforming the Future of Infrastructure through Smarter Information: Proceedings of the International Conference on Smart Infrastructure and Construction, 27-29 June 2016: 161-166.

Network Rail (2015). Climate change adaptation report 2015. https://cdn.networkrail.co.uk/wp-

content/uploads/2016/11/Climate-Change-Adaptation-Report2015_FINAL.pdf.

Singleton A et al. (2014). Evaluating sub-pixel offset techniques as an alternative to D-InSAR for monitoring episodic landslide movements in vegetated terrain. Remote Sensing of Environment 147: 133-144.

Smethurst JA et al. (2017). Current and future role of instrumentation and monitoring in the performance of transport infrastructure slopes. Quarterly Journal of Engineering Geology and Hydrogeology, 50(3), 271-286.

Thompson $\mathrm{V}$ et al. High risk of unprecedented UK rainfall in the current climate. Nature communications 8.1 (2017): 107.

Torres R et al. GMES Sentinel-1 mission. Remote Sensing of Environment 120 (2012): 9-24. 